Research Article

\title{
Evaluation of Government Ecological Environment Governance Effect from the Public's Perspective Based on the Entropy Method: Take the Kubuqi Desert in Inner Mongolia as an Example
}

\author{
Erhan Wu 1 and Zhiyi Gai (iD \\ College of Economics and Management, Inner Mongolia Agricultural University, Hohhot 010018, China \\ Correspondence should be addressed to Zhiyi Gai; gaizhiyi@imau.edu.cn
}

Received 21 October 2021; Revised 15 November 2021; Accepted 18 November 2021; Published 13 December 2021

Academic Editor: Tongguang $\mathrm{Ni}$

Copyright (c) 2021 Erhan Wu and Zhiyi Gai. This is an open access article distributed under the Creative Commons Attribution License, which permits unrestricted use, distribution, and reproduction in any medium, provided the original work is properly cited.

\begin{abstract}
The Kubuqi Desert is the seventh-largest desert in China. Under the leadership of the central, autonomous region and local governments, the ecological situation has undergone historic changes. In this paper, we select Hangjin Banner and Dalate Banner, which have the most widely distributed deserts and use 347 households as the research perspective to construct the evaluation index system of the government's ecological environment governance effect. The entropy method is used to evaluate the governance effect, and the ordinary least squares and quantile regression are used to compare the evaluation differences of different publics. The research found the following. (1) The public believes that the government's ecological governance measures have achieved good results in the third-level index analysis. The ecological environment in the desert area has been significantly improved; that is, the survival rate of trees has increased, the area of vegetation coverage and vegetation types have increased, and the frequency of sandstorms has decreased. However, the intensity of sandstorms and the flow of water sources did not change significantly. The various types of public income have increased significantly compared to before the governance. The public takes the ecological priority as the concept and actively participates in the government's governance implementation, which means that the ecological awareness and behavior are higher. (2) Among the second-level index, the weights and scores in descending order are public economic characteristics: $45.53 \%$ and 0.4840 , public ecological behavior: $25.62 \%$ and 0.1682 , public ecological effect perception: $18.35 \%$ and 0.1240 , and public ecological awareness: $10.51 \%$ and 0.0291 . The comprehensive evaluation result is 0.8054, which is in the first grade, and the effect is excellent. (3) The public comprehensive evaluation results of the two regions are similar. Hangjin Banner is 0.8209 and Dalate Banner is 0.8557 , both in the first grade. The effect is excellent. (4) In the OLS regression results, gender has a significant positive impact on evaluating the government's ecological environment governance effect. Age, ethnicity, and occupation have a significant negative impact. As the quintile increases, the influence of gender, age, and ethnicity first increases and then decreases. The maximum regression coefficient of gender at the $50 \%$ quantile is 0.714 , which has a significant positive effect. Age has a significant negative impact at each quantile. The regression coefficient of ethnicity at the $50 \%$ quantile is the highest -0.357 , which has a significant negative impact. Occupation only has a significant negative impact at the low quintile.
\end{abstract}

\section{Introduction}

In today's increasingly severe ecological environment problems, countries worldwide are actively exploring ways to realize the rational development and utilization of environmental resources. Over the years, the Inner Mongolia Autonomous Region, as one of the provinces with more severe ecological and environmental problems in China, has made some gratifying achievements and valuable experience in environmental governance. In particular, the ecological environment management of the Kubuqi Desert has become a representative case in environmental environment management, sand prevention, and control in the Inner Mongolia Autonomous Region, China, and even the world. In a 
broad sense, environmental governance refers to the management of human social and economic activities through the extensive use of financial, technological, legal, and administrative means within the scope of environmentally permitted capacity, following the scientific guidance of environmental theory. In a narrow sense, to achieve the expected environmental goals, managers should prevent and control the pollution impacts produced in social and economic development to achieve the unity of economical, social, and ecological benefits [1]. The United Nations Development Program (UNDP) and the United Nations Environment Program (UNEP) pointed out how to make environmental decisions and who makes decisions. This process is called environmental governance [2]. That is to say, environmental governance is the exercise of power over natural resources and the environment, including the decision-making process of laws and public institutions such as government agencies and village committees to make power specific. As the primary embodiment of national or local existence, government agencies occupy the core position and leading role in the governance of many fields [3], including the area of ecological environment governance.

Relying on the natural resources and climatic characteristics of the Kubuqi area, the government formulated a "focus on forest and animal husbandry, diversified management" from the end of the 1970s. Comprehensive management of the Kubuqi Desert began in the 1980s. The construction of "planting three and five small" (planting trees, planting grass, planting Caragana korshinskii, small watershed, small water conservancy, small fenced pasture, small economy, small farming, and animal husbandry machinery). Simultaneously, the desolate sand, empty beach, slope, desolate ditch, and desolate mountain are allocated to households to encourage planting trees and grass, managed by farmers and herders. In the 1990s, vegetation construction was regarded as the most significant infrastructure construction. During this period, the Kubuqi region implemented various ecological and economical projects following "resource development and environmental protection" principles, adapted to local conditions, classified guidance, regional implementation, and gradient promotion [4]. By 2000, the policy of "grazing prohibition, rest grazing, rotation grazing, stall-feeding and half-feeding, and transfer of farmers and herdsmen" will be implemented. The Kubuqi Desert is designated as a prohibited development zone. They are carrying out ecological immigration, guiding enterprises to join environmental governance, and building ecological industries of desert tourism, desert medicine, and circular desert economy $[4,5]$. After 2012, the Kubuqi region has practiced Xi Jinping's ecological civilization thought, incorporated desertification into the overall national economic and social development plan, and implemented a local administrative leadership responsibility system. And encourage the whole society to participate in ecological construction and increase the application of science and technology in environmental governance. The ecological situation has achieved a historic change. The international community has highly recognized Kubuqi's ecological governance achievements and experience. In 2014, the
United Nations Environment Program established the Kubuqi Desert Ecological Management Zone as a "Global Desert Ecological Economic Demonstration Zone." In 2015, the United Nations Climate Conference in Paris shared Kubuqi's desertification control as a "Chinese sample." In 2017, the United Nations released the world's first desert ecological wealth report and the world's first case of China's ecological civilization construction recognized by the United Nations and the international community [5].

Scholars are concerned about the macrolevel natural environment of the Kubuqi Desert [6], governance process, governance policies and measures, governance effectiveness (Qi Hailin, 2017) [5, 7], and empirical enlightenment $[8,9]$. The microlevel government-led ecological environment governance $[10,11]$, the effect of ecological migration [12], land use under governance policies $[13,14]$, and other aspects are less content. In particular, the research on governance effects based on the public's perspective is relatively lacking. The methods, indicators, and corresponding evaluation results are different based on evaluating the ecological environment governance effects of different subjects [15]. At present, the evaluation of ecological governance effects from the public's perspective includes analytic hierarchy process (AHP) decision analysis method [15], analytic hierarchy process (AHP)-fuzzy comprehensive evaluation (FCE) method [16], entropy method [17, 18], etc. Different methods have their advantages and disadvantages. In this paper, the entropy method is used to evaluate the governance effect. At the same time, the ordinary least squares regression and quantile regression are used to compare the evaluation differences of different publics. In this way, we provide help for follow-up governance.

\section{Materials and Research Methods}

\subsection{Overview of the Research Area}

2.1.1. Geographical Distribution Overview. The Kubuqi Desert is located on the northern edge of the Ordos Platform, on the southern bank of the Yellow River, facing the $\mathrm{Mu}$ Us Sandy Land in the south. It is 360 kilometers long from east to west and 40 kilometers wide from north to south. They are distributed in Hangjin Banner, Dalate Banner, Zhungeer Banner, Yijinhuoluo Banner, and Dongsheng District of Ordos City. However, they are mainly distributed in Hangjin Banner and Dalate Banner. Therefore, choose Hangjin Banner and Dalate Banner for analysis. In the mid-1990s (Table 1), the total area of the Kubuqi Desert was 18,500 square kilometers. The results of the $5^{\text {th }}$ China National Desertification and Sandification Inventory Monitoring show that the total area of the Kubuqi Desert is 14,100 square kilometers. Among them, the desert area in Hangjin Banner is 10,600 square kilometers, accounting for $75.37 \%$ of the total desert area. Dalate Banner covers an area of 2,386 square kilometers, accounting for $16.92 \%$. The two places account for $92.29 \%$ of the whole desert area. 
TABle 1: Kubuqi Desert in the mid-1990s and the 5th China National Desertification and Sandification Inventory Monitoring and distribution data comparison (unit $\mathrm{km}^{2}$ ).

\begin{tabular}{|c|c|c|c|c|c|c|c|}
\hline Statistical unit & $\begin{array}{l}\text { Desert } \\
\text { area }\end{array}$ & $\begin{array}{c}\text { Mobile } \\
\text { dune/ } \\
\text { land }\end{array}$ & $\begin{array}{c}\text { Accounted for the } \\
\text { total desert area } \\
(\%)\end{array}$ & $\begin{array}{l}\text { Semifixed } \\
\text { dune/land }\end{array}$ & $\begin{array}{l}\text { Accounted for the } \\
\text { total desert area } \\
(\%)\end{array}$ & $\begin{array}{c}\text { Fixed } \\
\text { dune/ } \\
\text { land }\end{array}$ & $\begin{array}{c}\text { Accounted for the } \\
\text { total desert area } \\
(\%)\end{array}$ \\
\hline Mid-1990s & 18517.85 & 9074.26 & 49.00 & 1675.28 & 9.05 & 7768.31 & 41.95 \\
\hline $\begin{array}{l}\text { The 5th China national } \\
\text { desertification and } \\
\text { sandification inventory } \\
\text { monitoring }\end{array}$ & 14111.52 & 5331.33 & 37.78 & 2532.59 & 17.95 & 5125.89 & 36.32 \\
\hline Hangjin Banner & 10635.85 & 4669.67 & 33.09 & 2342.84 & 16.6 & 2975.89 & 21.1 \\
\hline Dalate Banner & 2386.93 & 638.65 & 4.52 & 148.41 & 1.05 & 1331.53 & 9.43 \\
\hline
\end{tabular}

Note. The data comes from Yang Wenbin, The natural environment and comprehensive management of Kubuqi Desert [M], Inner Mongolia University Press, 2005 and data obtained from the survey.

\subsubsection{Socio-Economic Overview. Agriculture and animal} husbandry production: the total output value of farming, forestry, animal husbandry, and fishery in Hangjin Banner increased from 28.05 million yuan in 1978 to 4.020 billion yuan in 2020, an increase of $99.3 \%$; the total number of livestock and total grain output increased by $55.5 \%$ and $94.1 \%$, respectively, at the end of the year (Figure 1). The total output value of farming, forestry, animal husbandry, and fishery in Dalate Banner has increased from 36,47 million yuan in 1978 to $753,603.97$ million yuan in 2020, an increase of $99.52 \%$; the total number of livestock and total grain output increased by $75.6 \%$ and $91.1 \%$, respectively, at the end of the year (Figure 2). Regional economy: Hangjin Banner's GDP increased from 26.31 million yuan in 1978 to 12883.26 million yuan in 2020 , an increase of $99.8 \%$; public finance budget revenue, public finance budget expenditure, and per capita net income of farmers and herdsmen increased by $99.6 \%, 99.8 \%$, and $99.2 \%$, respectively (Figure 3). Dalate Banner's GDP increased from 53.63 million yuan in 1978 to 31969.72 million yuan in 2020 , an increase of $99.8 \%$; public finance budget revenue, public finance budget expenditure, and per capita net income of farmers and herdsmen increased by $99.8 \%$, $99.7 \%$, and $98.9 \%$, respectively (Figure 4 ).

\subsection{Data Sources}

2.2.1. Questionnaire Survey. From October 2019 to August 2021, the author selected 10 Sumu and towns (Table 2) in Hangjin Banner and Dalate Banner to conduct a random household questionnaire survey. A total of 405 questionnaires were issued, with 347 valid questionnaires, and the efficiency is $85.68 \%$.

2.2.2. Basic Information of the Sample. There are more males in the sample $(69.16 \%)$, and $60.81 \%$ of the interviewees are over 41 years old, and they have participated in the management of the Kubuqi Desert and the construction of desert-crossing highways. Among them, the Han nationality accounted for $62.54 \%$ and the Mongolian nationality accounted for $37.46 \%$. The education level of technical secondary school and above accounted for $50.72 \%$, and the overall educational level was relatively high. Half-agricultural and half-pastoral households accounted for the largest proportion of households, accounting for $23.63 \%$. "3-4 persons" accounted for the largest proportion of the family population, at $66.29 \%$. In terms of total household income and per capita net income, the proportion of each income segment varies greatly (Table 3).

\subsection{Research Methods}

2.3.1. Entropy Method. The entropy method can transform Kubuqi's public's subjective, long-term, and qualitative continuity judgments of the governance process into quantitative data [18]. The main steps of the entropy method to determine the weight coefficient:

(1) Construct the original data matrix:

$$
A=\left(x_{i j}\right), i=1,2, \ldots, 347, j=1,2, \ldots, 22,
$$

where $i$ represents the number of citizens participating in the evaluation and $j$ represents the number of evaluation indexes.

(2) Data standardization: the standardization basis for positive indexes and moderate indexes:

$$
x=\frac{x_{i j}-\min x_{i j}}{\max x_{i j}-\min x_{i j}} .
$$

The proportion of income from crops and the proportion of income from farming, which are moderate indexes, are standardized based on the average value within the group:

$$
x=\frac{\left|x_{i j}-\operatorname{avg} x_{i j}\right|}{\left|\operatorname{avg} x_{i j}-\min x_{i j}\right|} .
$$

(3) Unified quantification of indicators, calculating the weight of the $j$ th index,

$$
P_{i j}=\frac{x_{i j}}{\sum_{i=1}^{n} x_{i j}} .
$$

(4) Calculate the entropy value of the $j$ th index: 


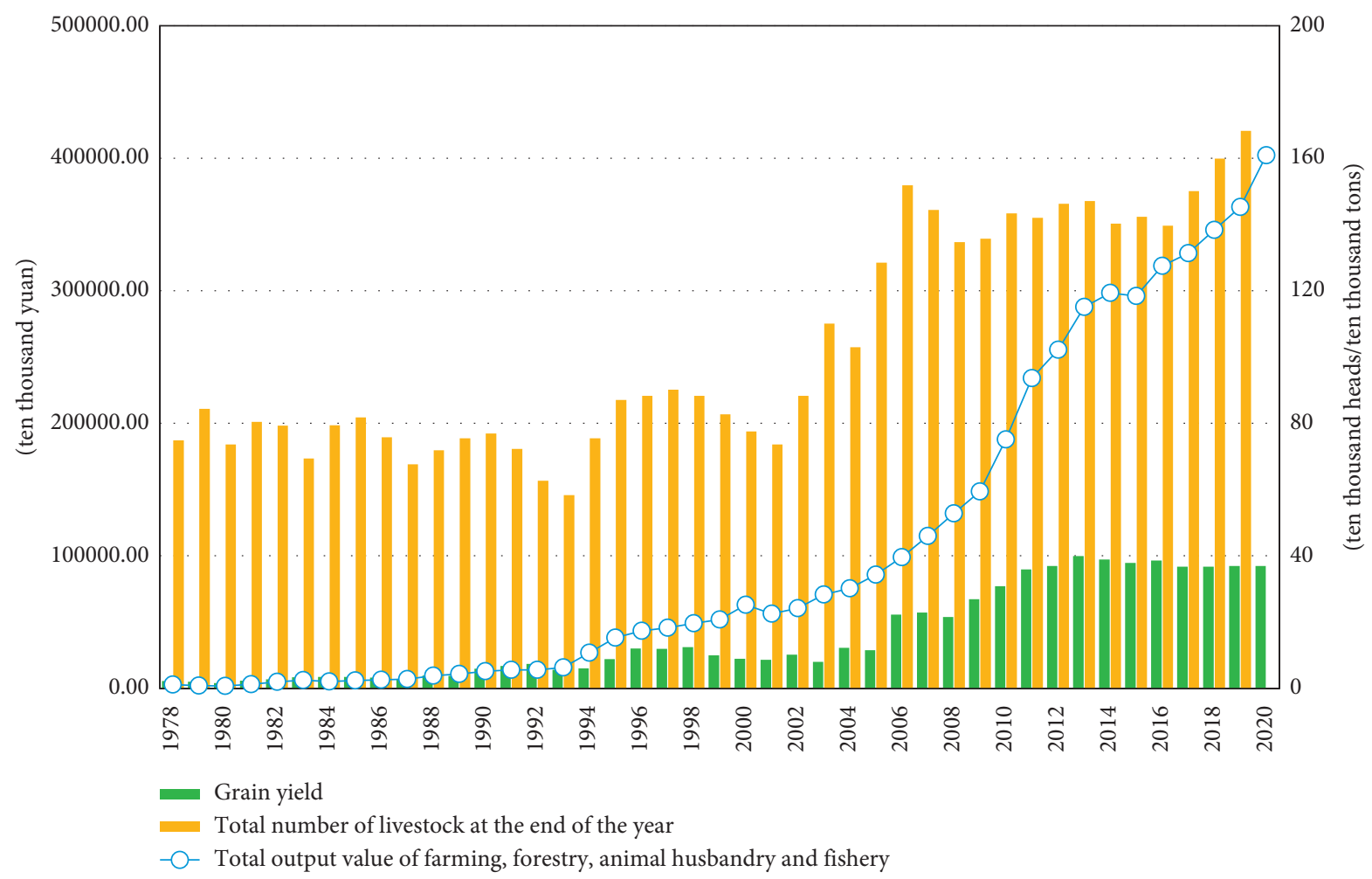

FIGURE 1: Main agricultural production statistics index of Hangjin Banner.

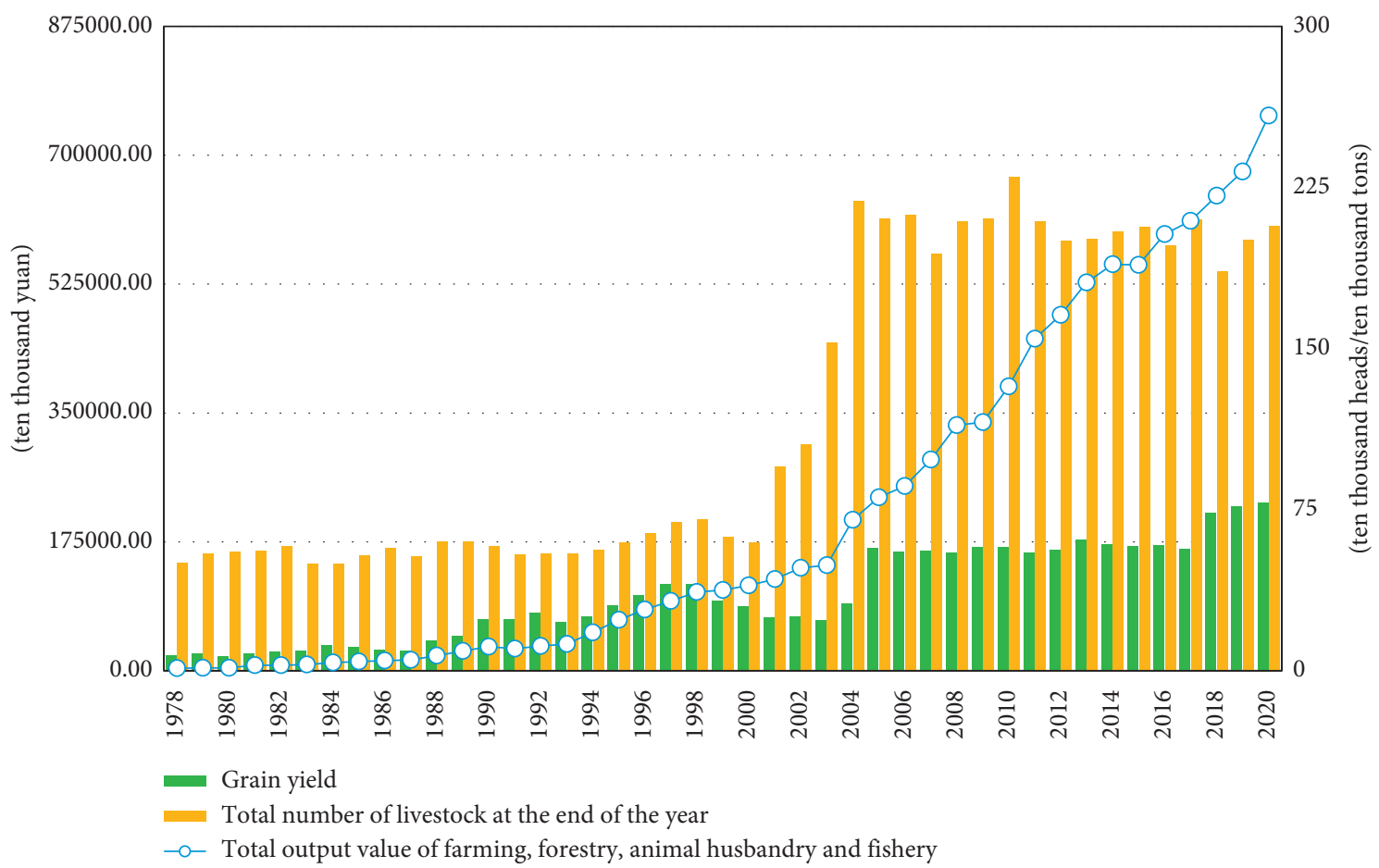

Figure 2: Main agricultural production statistics index of Dalate Banner. 


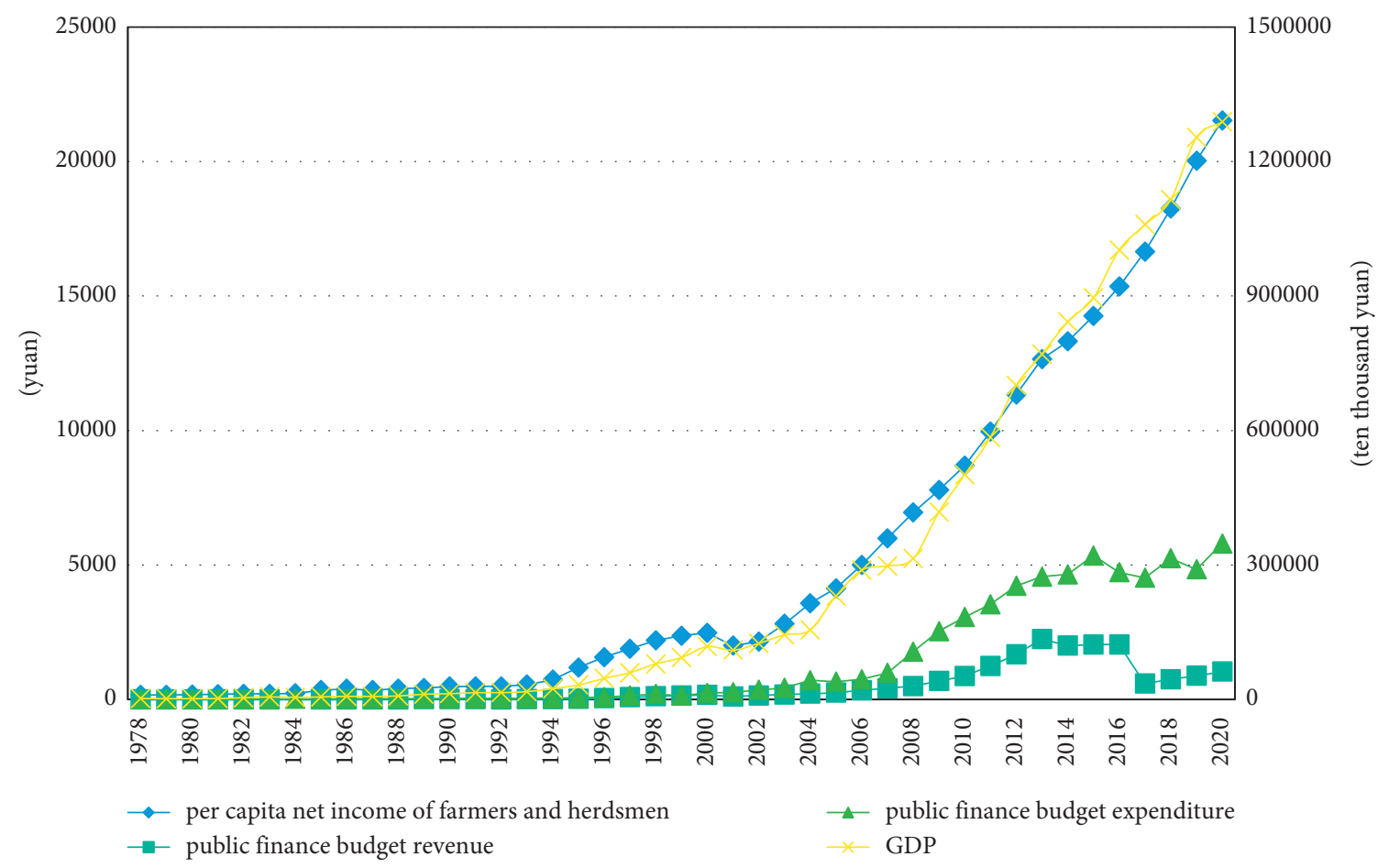

Figure 3: Main regional economic statistical index of Hangjin Banner.

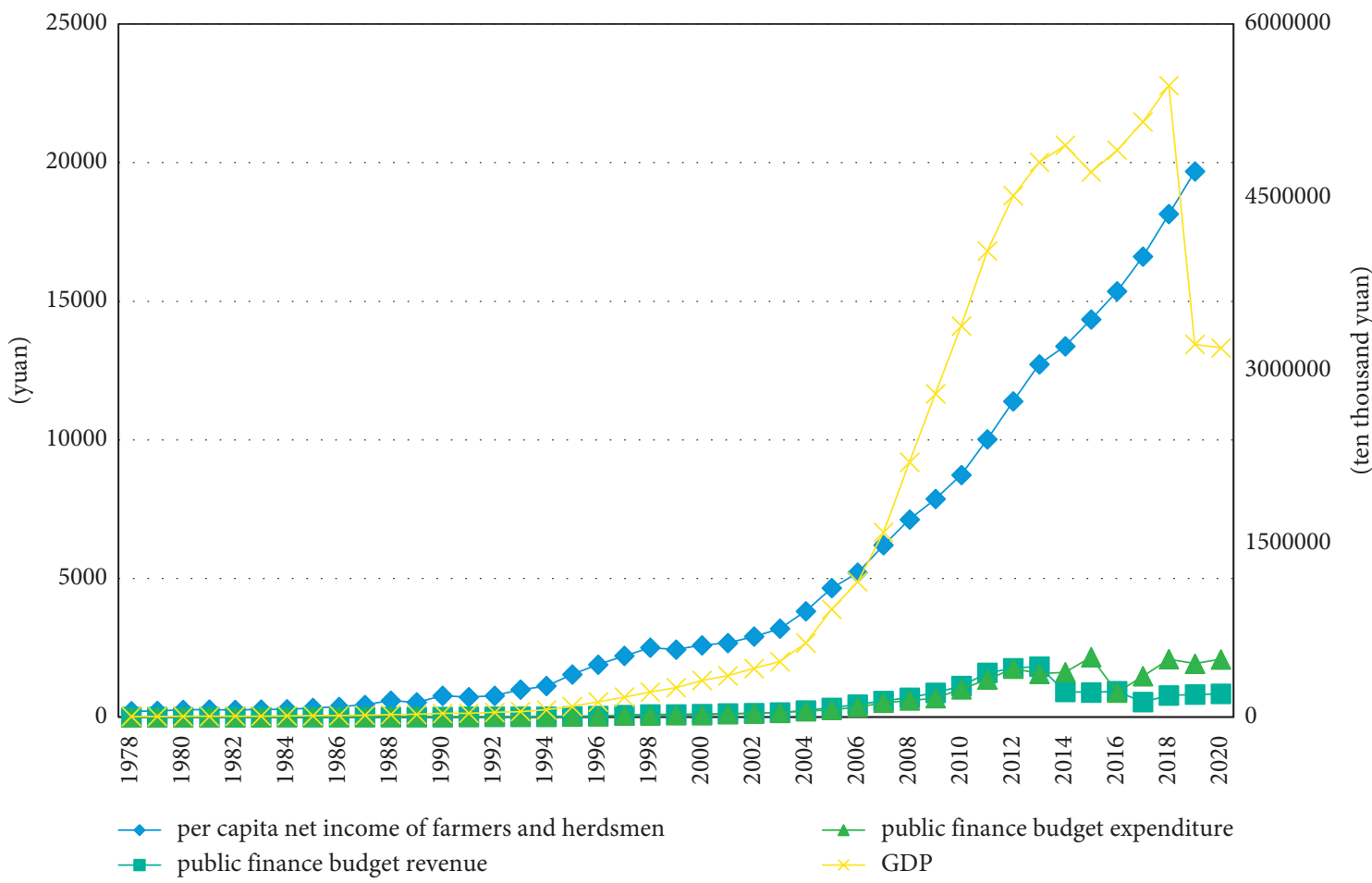

Figure 4: Main regional economic statistical index of Dalate Banner. Note. The data are derived from the "Inner Mongolia Statistical Yearbook," "Ordos Statistical Yearbook," and the statistics of the National Economic and Social Development Bulletin of Hangjin Banner and Dalate Banner in 2020. 
TABLE 2: Distribution of the sample area.

\begin{tabular}{lc}
\hline Banner county name & Sumu (town) \\
\hline $\begin{array}{l}\text { Hangjin Banner } \\
\text { Dalate Banner }\end{array}$ & Engebei Town, Zhandanzhao Sumu, Shulinzhao Sumu, Wangaizhao Town, Bainijing Town, and Zhonghe West \\
Town
\end{tabular}

TABle 3: Descriptive statistics of sample data.

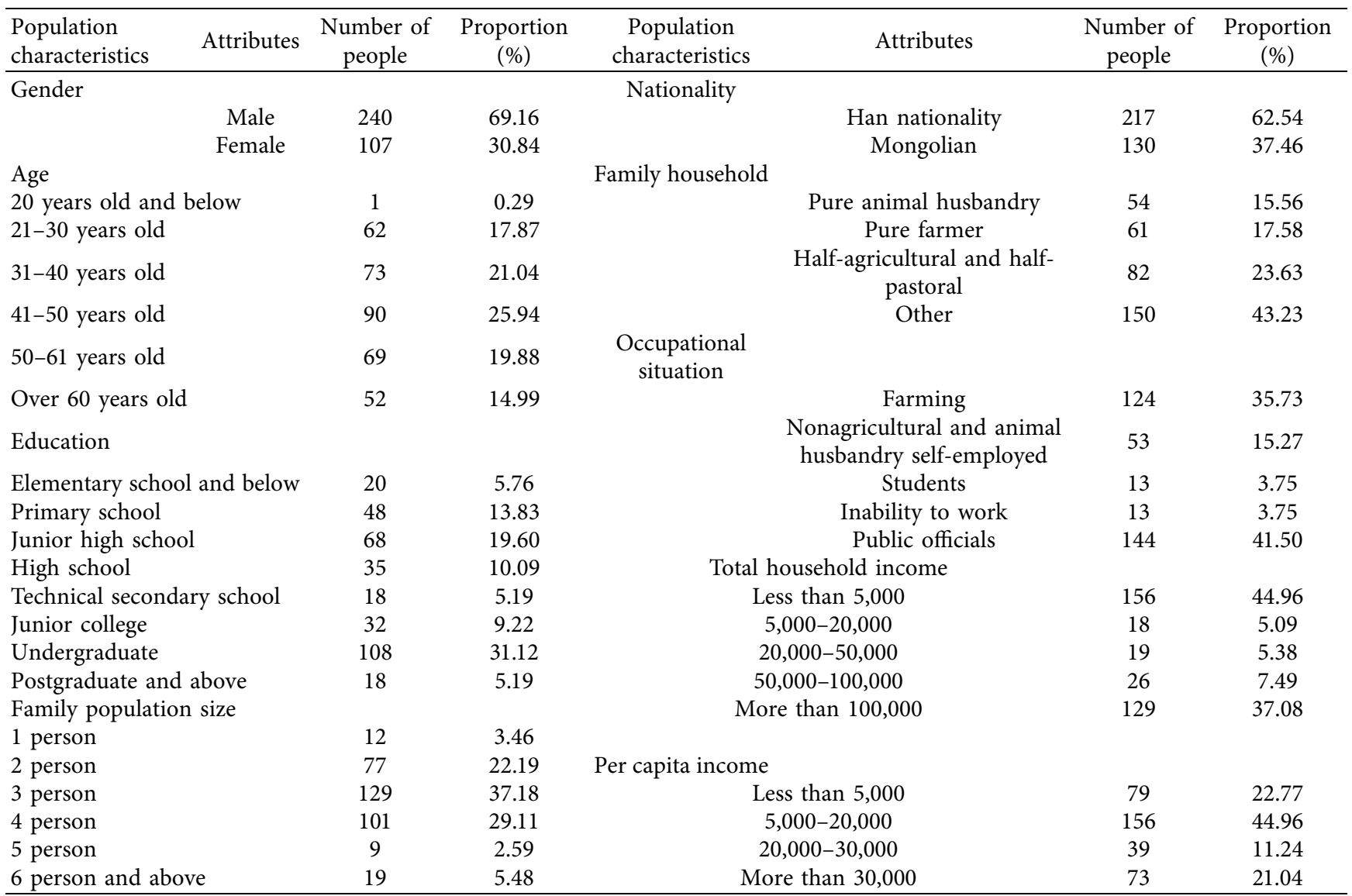

$e_{j}=-k \sum_{i=1}^{n} P_{i j} \ln P_{i j}$, where $\mathrm{k}$ is equal to $\frac{1}{\ln i}, \mathrm{k}>0$.

(5) Calculate the difference coefficient of the $j$ th index:

$$
g_{j}=1-e_{j}
$$

(6) Calculate the weight of the jth index:

$$
w_{j=} \frac{g_{j}}{\sum_{j-1}^{m} g_{j}},
$$

$w_{j}$ is the final weight of each quantified third-level evaluation index. According to the principle of additivity of the index at the same level [17], the second-level index weight is the sum of the corresponding third-level index weights and can be obtained the first-level index weight in the same way.

(7) Calculate the public's evaluation of the effect of ecological governance:

$$
E_{j}=\sum w_{j} x_{j}
$$

According to the principle of the additivity of the statistical index scores of the entropy method [17], the second-level index score is the weighted summation of the corresponding third-level index scores and can be obtained the first-level index score in the same way.

2.3.2. Quantile Regression. Quantile regression has strong robustness for outliers, normality of dependent variables, or heteroscedasticity problems [18]. The model is as follows:

$$
y_{q}\left(x_{i}\right)=x_{i} \beta_{q}
$$

where $y$ is the evaluation result of the public's ecological governance effect, $x_{i}$ is the factor that affects the public evaluation result, and $\beta_{q}$ represents the $q$-quantile regression coefficient, and its value is 


$$
\beta_{q}=\min \sum_{i: y_{i} \geq \beta_{q} x_{i}}^{n} q\left|y_{i}-\beta_{q} x_{i}\right|+\sum_{i: y_{i}<\beta_{q} x_{i}}^{n}(1-q)+\left|y_{i}-\beta_{q} x_{i}\right| .
$$

\section{Results and Analysis}

3.1. Construction of the Evaluation Index System. Based on the principles of systematicity, pertinency, stability, discrepancy, and measurability $[17,18]$, we refer to relevant domestic and foreign literature [18]:

(1) The public's perception of the ecological effects of governance

(2) Influence the effects of ecological governance

(3) The level of public economic development is affected by or related to ecological governance

(4) The public's willingness to participate in ecological governance and environmental awareness, respectively, correspond to the four second-level indicator standards

That is the public's perception of ecological effects, ecological behavior, their economic level, and ecological awareness. Under each second-level index, several thirdlevel indexes are set as the scheme layer. See Table 4, for specific indicators and connotations.

3.2. Overall Evaluation Results. To directly reflect the effect of ecological environment governance, scholars divide the evaluation index of government ecological environment governance effect into five grades $[17,18]$, see Table 5.

3.2.1. Third-Level Index Result. In the third-level index (Table 6), the index factor value is the average value of the same sample data as the evaluation value. C1, C2, C4, and C5 are positive indicators with evaluation grades ranging from $1-5$. Their factor values are all greater than 4 , indicating that the public perceives that the ecological environment of the Kubuqi area under the government's leadership has significantly improved, that is, the survival of trees has increased, the area covered by vegetation, and the types of vegetation have increased. At the same time, the frequency of sandstorms has decreased a lot. Still, the intensity of C3 sandstorms and the flow of C6 water sources have not changed significantly. $96.25 \%$ of the people in the questionnaire believe that the environment in the sandy area has been significantly improved. As of 2016, the governance area of the Kubuqi Desert reached 6,460 square kilometers and a green area of more than 3,200 square kilometers. The forest and vegetation coverage has increased from $0.8 \%$ and $16.2 \%$ in 2002 to $15.7 \%$ and 53\% [5]. Among them, the artificial afforestation area of Hangjin Banner and Dalate Banner in 2019 was 10.41 thousand hectares and 5.17 thousand hectares, an increase of $76.4 \%$ and $19.7 \%$ over 2018. Dust weather decreased from more than 50 times in 1988 to one time in 2016, rainfall increased from less than $100 \mathrm{~mm}$ to
$456 \mathrm{~mm}$, and biodiversity increased to more than 530 types [5].

$\mathrm{C} 8, \mathrm{C} 20$, and $\mathrm{C} 22$ indicate that the public believes that the government's ecological governance measures have achieved specific results, with high satisfaction and confidence in sustainable governance. An average of $93.85 \%$ of the respondents in the questionnaire also agreed that the Kubuqi Desert governance is a scientific and successful governance case, and it will have better development in the future. $\mathrm{C} 13$ is the weight and score of the channel type for obtaining ecological policy information are the second, occupying the central position, indicating that getting governance policy information is one of the public's evaluation criteria for the effectiveness of government governance. If the public information is not comprehensive enough, not transparent enough, and asymmetrical, it will make the overall government governance become water without a source and a tree without roots. C14, C15, C16, and $\mathrm{C} 17$ are the rate of change and satisfaction of various incomes before and after ecological governance. The weights and scores are all the top 5, indicating that multiple revenues such as agriculture, animal husbandry, labor, and government subsidies have increased significantly compared to before the governance. The government's ecological migration policy provides a monthly social security subsidy of 350 yuan per person in addition to cash and housing subsidies for herders in sandy areas. Guide enterprises to transfer more than 1.5 million acres of sandy land to farmers and herdsmen in sandy areas, and farmers and herdsmen also earn income through land entering agriculture. Since 2017, 12 villages and towns around Kubuqi have more than 5,500 people through the traditional Chinese medicinal planting model represented by licorice have been benefited. C9 and C10 indicate that taking others as the reference object, the respondents believe their sand area activities are significantly less than others. This result may be due to the external expected pressure brought by the questionnaire to the respondent. There may be a self-perception bias, which will eventually lead to biased results. C19, C21, C11, C12, and $\mathrm{C} 18$ indicate that the public prioritizes ecology, which means they have higher ecological awareness and behavior.

3.2.2. Second-Level Index Results. In the second-level index results (Table 6), the weights and scores in the descending order are B3 public economic characteristics $45.53 \%$ and 0.4840 , B2 public ecological behavior $25.62 \%$ and 0.1682 , B1 ecological effect perception $18.35 \%$ and 0.1240 , and B4 public ecological awareness $10.51 \%$ and 0.0291 . It shows that the government should prioritize economic construction and ecological behavior in the process of governance. 93.65\% of the people said that the ecological environment governance has significantly improved the region and their economy. Also, $92.5 \%$ of the people felt that the governance had brought positive social benefits. In recent years, the economy of Kubuqi has continued to develop, creating a desert economy with the integration of the tertiary industry and complementing each other, which has driven 102,000 people out of poverty. Their income has increased from less 


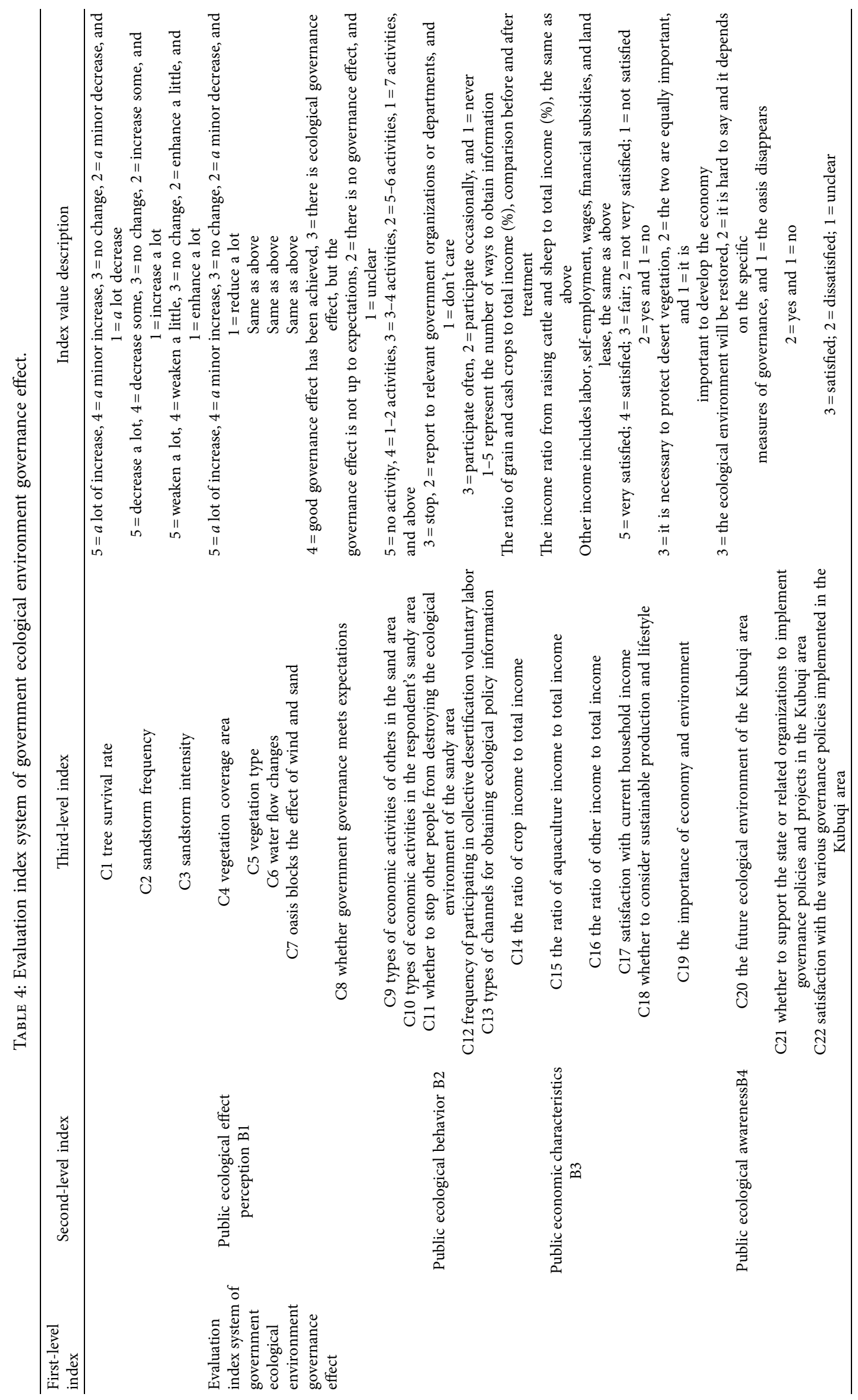


TABLE 5: The grading standard of the government's ecological environment governance effect evaluation index.

\begin{tabular}{lccccc}
\hline Grade & 1 & 2 & 3 & 4 & 5 \\
\hline Evaluation index & $0.8-1.0$ & $0.6-0.8$ & $0.4-0.6$ & $0.2-0.4$ & $<0.2$ \\
Meaning & Excellent & Good & Ordinary & Poor & Very bad \\
\hline
\end{tabular}

TABLE 6: Empirical results of evaluation of government ecological environment governance effects.

\begin{tabular}{|c|c|c|c|c|c|c|c|c|c|}
\hline \multicolumn{6}{|c|}{ Third-level index } & \multicolumn{3}{|c|}{ Second-level index } & \multirow{2}{*}{$\begin{array}{c}\text { First-level index } \\
\text { Overview }\end{array}$} \\
\hline Index & Entropy & Difference coefficient & Index factor value & Index weight & Score & Index & Index weight & Score & \\
\hline $\mathrm{C} 1$ & 0.9962 & 0.0038 & 4.4300 & 0.0172 & 0.0762 & \multirow{8}{*}{$\mathrm{B} 1$} & \multirow{8}{*}{0.1835} & \multirow{8}{*}{0.1240} & \multirow{22}{*}{ A 0.8054} \\
\hline $\mathrm{C} 2$ & 0.9958 & 0.0042 & 4.4100 & 0.0192 & 0.0847 & & & & \\
\hline $\mathrm{C} 3$ & 0.9951 & 0.0049 & 2.7700 & 0.0224 & 0.0620 & & & & \\
\hline $\mathrm{C} 4$ & 0.9967 & 0.0033 & 4.4800 & 0.0152 & 0.0681 & & & & \\
\hline $\mathrm{C} 5$ & 0.9967 & 0.0033 & 4.3800 & 0.0149 & 0.0653 & & & & \\
\hline C6 & 0.9897 & 0.0103 & 3.6500 & 0.0469 & 0.1712 & & & & \\
\hline $\mathrm{C} 7$ & 0.9968 & 0.0032 & 2.8300 & 0.0147 & 0.0416 & & & & \\
\hline $\mathrm{C} 8$ & 0.9927 & 0.0073 & 3.2400 & 0.0330 & 0.1069 & & & & \\
\hline C9 & 0.9957 & 0.0043 & 3.7800 & 0.0194 & 0.0733 & \multirow{5}{*}{$\mathrm{B} 2$} & \multirow{5}{*}{0.2562} & \multirow{5}{*}{0.1682} & \\
\hline $\mathrm{C} 10$ & 0.9969 & 0.0031 & 4.0300 & 0.0139 & 0.0560 & & & & \\
\hline $\mathrm{C} 11$ & 0.9937 & 0.0063 & 2.5300 & 0.0286 & 0.0724 & & & & \\
\hline C12 & 0.9896 & 0.0104 & 2.2200 & 0.0472 & 0.1048 & & & & \\
\hline C13 & 0.9676 & 0.0324 & 2.3800 & 0.1471 & 0.3501 & & & & \\
\hline $\mathrm{C} 14$ & 0.9638 & 0.0362 & 1.9000 & 0.1643 & 0.3122 & \multirow{4}{*}{ B3 } & \multirow{4}{*}{0.4553} & \multirow{4}{*}{0.4840} & \\
\hline C15 & 0.9690 & 0.0310 & 1.6600 & 0.1405 & 0.2332 & & & & \\
\hline C16 & 0.9752 & 0.0248 & 3.4500 & 0.1127 & 0.3888 & & & & \\
\hline C17 & 0.9917 & 0.0083 & 3.4100 & 0.0378 & 0.1289 & & & & \\
\hline $\mathrm{C} 18$ & 0.9968 & 0.0032 & 1.9700 & 0.0147 & 0.0290 & \multirow{5}{*}{ B4 } & \multirow{5}{*}{0.1051} & \multirow{5}{*}{0.0291} & \\
\hline C19 & 0.9927 & 0.0073 & 2.1900 & 0.0330 & 0.0723 & & & & \\
\hline $\mathrm{C} 20$ & 0.9952 & 0.0048 & 2.4400 & 0.0218 & 0.0532 & & & & \\
\hline C21 & 0.9978 & 0.0022 & 1.9500 & 0.0099 & 0.0193 & & & & \\
\hline $\mathrm{C} 22$ & 0.9943 & 0.0057 & 4.0100 & 0.0257 & 0.1031 & & & & \\
\hline
\end{tabular}

than 400 yuan to the current 14,000 yuan. The government benefits farmers and herdsmen through comprehensive measures such as letting farmers and herdsmen circulate sand to plant grass and trees, build infrastructure, government support, employment assistance, and education and training. Three new immigrant villages in Hangjin Banner, Yanhaizi, Daotugacha, and Hangjinnaoer have been built successively, with 333 households and 840 people of ecological immigrants [19]. The ecological behavior of the public in the sandy areas started in 1980 with the government's decision of "vegetation construction is the largest infrastructure construction" and the "decision to plant trees, grasses, and caragana korshinskii with 1 million mu each year." At this stage, numerous professional afforestation households have emerged.

By the end of the 1990s, under the guidance of the government, the public began to participate in the construction of the "desert-crossing highway" (Hangjin Banner Desert-Crossing Highway, also known as the Poverty Alleviation and Development Highway from Xini Town to Wulashan Town), with a total length of 115 kilometers. After entering 2000, the government-supported and encouraged farmers and herdsmen to carry out joint-stock development, taking the form of operation or participation of enterprises + bases and companies + farmers and herdsmen, extending the land contract period and service life, and auctioning them at low prices. The government also adopted free allocation of sandy land to large households for governance, exempted 3-5 years of fees, and allowed inheritance and transformation of sandy land after development. It also implements regular tax reductions and exemptions for the agricultural and sideline products processing industries of the people in the sandy area to guide the public become the main participants in the governance of Kubuqi. Only during the Tenth Five-Year Plan of China period, 713 large households with more than 500 acres of sand control and afforestation were formed, including Wurigendalai and Feng Zhiting. These people have afforested an area of 1.02 million mu, accounting for $20 \%$ of the total afforestation area in Ordos City (Qi Hailin, 2017) [5]. Based on consolidating the achievements of economic and ecological behavior construction, we should strengthen the perception of ecological effects. The ecological awareness weight and score are the lowest $10.51 \%$ and 0.0291 . The research team found that farmers and herdsmen living in desert areas participated more in governance, while the public participation far from the desert areas was less.

3.2.3. First-Level Index Results. The comprehensive evaluation result is 0.8054 (Table 6), which is in the first grade, and the effect is excellent. In general, under the guidance of the ecological projects and policies of the central, autonomous region, and local governments, the ecological conditions of the Kubuqi Desert have achieved historical changes. In 
particular, since 2012, practicing Xi Jinxing's ecological civilization thought and the idea that "clear waters and green mountains are as good as mountains of gold and silver," we promote green transformation and development and implement the policy of giving priority to conservation, protection, and natural restoration, providing necessary conditions for governance.

\subsection{Evaluation Results of the Public in Different Regions.} The public comprehensive evaluation results of the two regions are similar (Figure 5). Hangjin Banner is 0.8209 and Dalate Banner is 0.8558 , both in the first grade with excellent results. From their respective composition, the evaluation of each part of Dalate Banner is relatively balanced. In terms of public ecological behavior and public ecological awareness, the public in Hangjin Banner is slightly higher than the public in Dalate Banner, which is related to the main distribution of the Kubuqi Desert in Hangjin Banner. As a result, the public has an intuitive comparison and more active participation in increasing various incomes before and after governance.

\subsection{Evaluation Differences of Different Public Heterogeneity}

3.4.1. Independent Variable Diagnosis. Ten public attributes such as gender, age, and educational level are selected as independent variables. The public's evaluation of the government's ecological environment governance effect is used as the dependent variable. After the stepwise regression of the above indicators, the explanatory power of education level, household population, household category, annual crop income, annual breeding income, and annual other income is weak and not significantly so eliminated. $R^{2}$ in Table 7 is 0.223 , meaning that gender, age, ethnicity, and occupation can explain $22.3 \%$ of the change in the public's evaluation of the government's eco-environmental governance effect. The model passed the F-test $(F=24.559$, $p<0.001)$. The VIF values are all less than 5 , there is no collinearity problem, the $\mathrm{D}-\mathrm{W}$ value is near the number 2 , there is no autocorrelation, and there is no correlation between the sample data.

For heteroscedasticity, two methods of the White test and the BP test are used to test. The null test hypothesis is that the model has no heteroscedasticity, which shows that both tests accept the null hypothesis $(p>0.05)$, and there is no heteroscedasticity problem (Table 8 ).

3.4.2. OLS Regression Results. In OLS regression (Table 9), the regression coefficient value of gender is 0.552 and passes the significance of 0.01 , producing a significant positive correlation. It shows that gender has a greater impact on the public's evaluation of ecological governance results. Compared with female respondents, male respondents have a higher evaluation of governance effects. It may be that men are more sensitive to and concerned about policies than women and have a more objective judgment on implementing policies. In contrast, women often rely on intuitive feelings. The age passes the significance of 0.01 , and the coefficient is negative, indicating that the older the age, the lower the evaluation of the effect of ecological governance. The national regression coefficient value is -0.308 ; through the significance of 0.05 , there is a significant negative correlation. The regression coefficient value of occupation is -0.113 , passing the significance of 0.01 , which produces a significant negative correlation.

3.4.3. Quantile Regression Results. In quantile regression (Table 9), the regression coefficient of gender at the $50 \%$ quantile is the highest at 0.714 . The quantile $25 \%$ and $50 \%$ pass the 0.01 significance test, and the $75 \%$ quantile pass the 0.05 significance test. The regression coefficient of age is the highest at the $50 \%$ quantile -0.357 , and each quantile passed the significance test of 0.01 . The regression coefficient of nationality is the highest at the $50 \%$ quantile -0.357 , which passes the significance test of 0.05 , and the other quantiles pass the significance test of 0.01 . The regression coefficient of occupation rose from -0.200 to -0.000 and only passed the significance test of 0.01 at the $25 \%$ quantile, while the other quantiles were not significant.

\section{Discussion}

The research results in this article show that the ecological awareness weight and score are the lowest. Therefore, even in advanced new technologies, the ecological environment is essential for human coexistence and development. This is "too rich nature makes people inseparable from the hands of nature, just like children cannot do without the lead belt." [20] To resolve this contradiction, it is necessary to strengthen the ecological consciousness of the people in it, that is, environmental problems originate from the behaviors caused by people's misconceptions and consciousness, and the ecological environment governance is actually the governance of people. The public is the micromain body of Kubuqi governance and the driving force to promote sustainable environmental governance. However, according to research findings, Kubuqi's ecological governance is still in an embarrassing situation where the majority of people benefit from government-led support and a few people participation. First of all, farmers and herdsmen living in the desert area are doing their best for the management of the Kubuqi Desert, while the public far away from the desert area lacks the awareness and enthusiasm to participate in the ecological environment management and even thinks that it has nothing to do with them, which leads to the overall governance efforts are not enough. Secondly, governance activities are formalized and the channels through which the public can participate in governance are relatively simple. For example, civil servants and enterprise employees of the local government administration department of Hangjin Banner participate in tree planting and greening every year only through the tree planting day and tree planting week organized by the local government or party organizations' day activities. It is inevitable to be absent from time to time in the governance process, and the ecological awareness and 


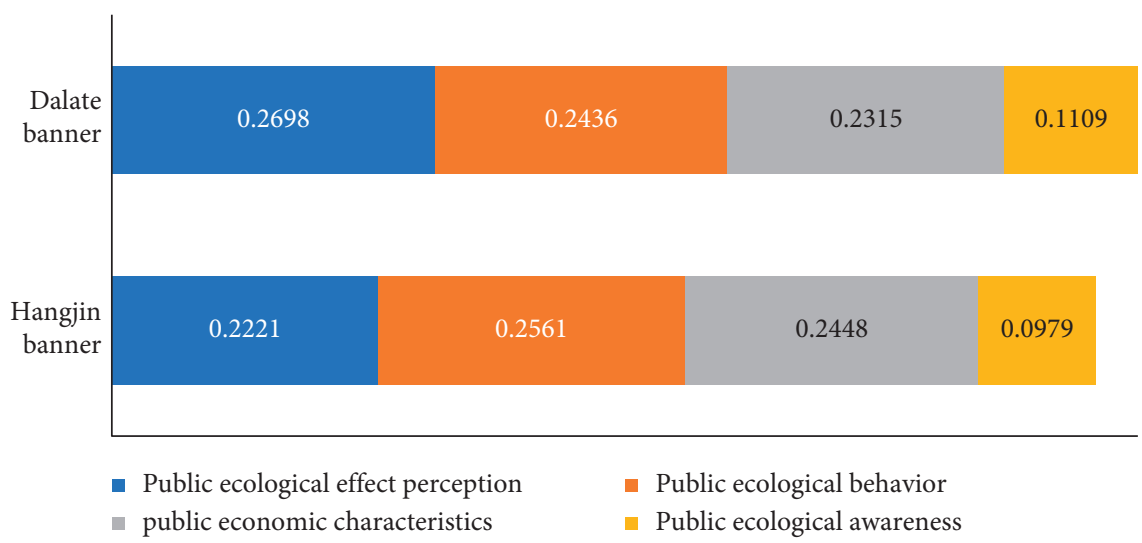

FIgURE 5: Comparison of public evaluation results between Hangjin Banner and Dalate Banner.

TABLE 7: Results of stepwise regression analysis.

\begin{tabular}{lccc}
\hline & Regression coefficient & $95 \%$ CI & VIF \\
\hline Constant & $4.339^{* *}(11.262)$ & $3.584 \sim 5.094$ & - \\
Gender & $0.568^{* *}(3.971)$ & $0.288 \sim 0.849$ & 1.093 \\
Age & $-0.384^{* *}(-7.449)$ & $-0.484 \sim-0.283$ & 1.156 \\
Nationality & $-0.328^{*}(-2.498)$ & $-0.586 \sim-0.071$ & 1.012 \\
Profession & $-0.088^{* *}(-2.839)$ & $-0.149 \sim-0.027$ & 1.075 \\
Sample size & & 347 & 0.223 \\
$R^{2}$ & & 0.214 & \\
Adjust $R^{2}$ & & $F(4,342)=24.559, p \leq 0.001$ \\
F value & & & \\
\hline
\end{tabular}

$\mathrm{D}-\mathrm{W}$ value: $1.752,{ }^{*} p<0.05$ and ${ }^{*} * p<0.01$, and $T$ value in parentheses.

TABLE 8: Results of the heteroscedasticity test.

\begin{tabular}{lccc}
\hline White heteroscedasticity test & & BP heteroscedasticity test \\
\hline$\chi^{2}$ & $p$ & $\chi^{2}$ & $p$ \\
15.375 & 0.636 & 2.454 & 0.783 \\
\hline
\end{tabular}

TABLE 9: Comparison of OLS regression and quantile regression results.

\begin{tabular}{lcccc}
\hline & OLS & Quantile $25 \%$ & Quantile $50 \%$ & Quantile $75 \%$ \\
\hline Constant & $3.930^{* *}(7.991)$ & $4.000^{* *}(8.847)$ & $3.857^{* *}(8.416)$ & $5.500^{* *}(9.271)$ \\
Gender & $0.552^{* *}(3.846)$ & $0.600^{* *}(3.660)$ & $0.714^{* *}(4.195)$ & $0.500 *(2.396)$ \\
Age & $-0.332^{* *}(-5.155)$ & $-0.400^{* *}(-7.073)$ & $-0.357^{* *}(-5.831)$ & $-0.500^{* *}(-6.667)$ \\
Nationality & $-0.308^{*}(-5.155)$ & $-0.400^{* *}(-2.747)$ & $-0.357^{*}(-2.284)$ & $-0.500^{* *}(-2.669)$ \\
Profession & $-0.113^{* *}(-3.126)$ & $-0.200^{* *}(-5.382)$ & $-0.071(-1.932)$ & $-0.000(-0.000)$ \\
Sample size & 347 & 347 & 347 & 347 \\
$R^{2}$ & 0.227 & 0.074 & 0.166 & 0.101 \\
\hline
\end{tabular}

${ }^{*}$ denotes $p<0.05,{ }^{* *}$ denotes $p<0.01$, and $T$ value is in parentheses

sense of responsibility are weak. Therefore, the government should conduct targeted and dynamic propaganda against these groups [21], cultivating personal ecological consensus and reshaping ecological concepts.

In addition, obtaining governance policy information is an important criterion for the public to evaluate governance. Therefore, an open and transparent information-sharing mechanism should be embedded in the policy system to break the information "islands" between different subjects and different fields for "sharing governance" and two-way communication [22]. Moreover, it has a smooth information dissemination system to ensure the objective authenticity of its dissemination of information. There should also be a mechanism for other subjects' normal participation and 
institutional guarantees for classifying, solving, and responding to problems based on multiparty induction and integration. This can encourage the establishment of an institutional trust system between environmental information among various subjects and enhance the effectiveness of environmental governance.

Furthermore, suppose the government increases the transparency of its operations and allows other subjects to express policy preferences and dissatisfaction through various channels. In that case, people will increase their confidence in the political system's fairness, stability, and predictability. In turn, confidence in the system can enhance people's sense of trust in each other [23]. "The role of trust is like a lubricant; it makes the operation of groups or organizations more effective [24]," thereby promoting Kubuqi ecological governance affairs.

\section{Conclusion}

(1) The analysis of the third-level index shows that the public believes that the government's ecological governance measures have achieved good results. The ecological environment in the desert area has been significantly improved. The survival rate of trees has increased, the area of vegetation coverage and vegetation types has increased, and the frequency of sandstorms has decreased. However, the intensity of sandstorms and water flow is not a significant change. The various types of public income have increased significantly compared to before the governance. The public takes the ecological priority as the concept and actively participates in the government's governance implementation, which means that the ecological awareness and behavior are higher.

(2) In the second-level index, the weights and scores in the descending order are public economic characteristics $45.53 \%$ and 0.4840 , public ecological behavior $25.62 \%$ and 0.1682, ecological effect perception $18.35 \%$ and 0.1240 , and public ecological awareness $10.51 \%$ and 0.0291 . The comprehensive evaluation result is 0.8054 , the grade is 1 , and the effect is excellent.

(3) The public comprehensive evaluation results of the two regions are similar, with Hangjin Banner being 0.8209 and Dalate Banner being 0.8557.

(4) In the OLS regression results, gender has a significant positive impact on evaluating the government's ecological environment governance effect. Age, ethnicity, and occupation have a significant negative impact. As the quintile increases, the influence of gender, age, and ethnicity first increases and then decreases. The maximum regression coefficient of gender at the $50 \%$ quantile is 0.714 , which has a significant positive effect. Age has a significant negative impact at each quantile. The regression coefficient of ethnicity at the $50 \%$ quantile is the highest -0.357 , which has a significant negative impact. Occupation only has a significant negative impact at the low quintile.

\section{Data Availability}

The data used to support the findings of this study can be obtained from the corresponding author upon request.

\section{Conflicts of Interest}

The authors declare that there are no conflicts of interest regarding the publication of this paper.

\section{Acknowledgments}

This work was supported by the 2019 National Social Science Fund Annual Project "Research on Ecological Environment Protection of Kubuqi Desert in Inner Mongolia for 40 Years of Reform and Opening-up" (19BMZ139).

\section{References}

[1] R. Fang, Environmental Dictionary, Science Press, Beijing, 2003.

[2] Wri, Word Resources Institute(WRI), 2002-2004: Decisions for the Earth-Balance, United Nations Development Programme (UNDP) United Nations Environment Programme(UNEP) World Bank, Word Resources WRI, Voice, And Power Washington, DC, 2003.

[3] L. Xin, Research on Government Responsibility in the Process of National Governance Modernization, Jilin University, Changchun, China, 2017.

[4] H. Qi, R. Bai, and Y. Xiao, The Process of Ecological Construction in the Ordos, Inner Mongolia People's Publishing House, Hohhot, China, 2017.

[5] Z. Gai, C. Yu, L. Su, A. Jiang, and E. Wu, Road to Rising: A Series of 40 Years of Reform and Opening up in Ordos City Ecological Metamorphosis -A Global Model of Green Development, Inner Mongolia People's Publishing House, Hohhot, China, 2019.

[6] W. Yang, Natural Environment and Comprehensive Management of Kubuqi Desert, Inner Mongolia University Press, Mongolia, China, 2005.

[7] Z. Wang, H. Qi, R. Bai, and Y. Xiao, Green Ordos in Combating Desertification, Inner Mongolia People's Publishing House, Hohhot, China, 2017.

[8] Y. Ma and R. Lu, Dare to Ask Kubuqi, Yuanfang Publishing House, Hohhot, China, 2014.

[9] Z. Wang, C. Yang, and D. M. Liujin, China's Kubuqi Targeted Poverty Alleviation Documentary, Tianjin Science and Technology Press, Tianjin, 2021.

[10] K. Li, Research on Desertification Control in Inner Mongolia under the Domination of the Government, Inner Mongolia University, Mongolia, China, 2016.

[11] Y. Liu, Research on the Countermeasures of Desertification Control in Hangjin Banner, Inner Mongolia from the Government's Perspective, Inner Mongolia Agricultural University, Mongolia, China, 2019.

[12] H. Alatengqimuge, "The research report on the construction of ecological civilization in the Kubuqi Desert-taking Hangjin banner prohibited development Zone as an 
example," Environment and Development, vol. 28, no. 05, pp. 1-6, 2016.

[13] M. Zhao, L. Zhou, Y. Chen, M. Gu, X. Guo, and R. Wang, "The impact of grazing prohibition policy on the land use behavior of farmers in the Kubuqi Desert," China Desert, vol. 37, no. 04, pp. 802-810, 2017.

[14] Z. Wang, Research on the Benefits of Desertification Land Utilization in Ordos City Based on the Development of Sand Industry, Inner Mongolia Normal University, Mongolia, China, 2019.

[15] S. Fan, H. Zhang, and Wuriga, Institutional Analysis and Performance Evaluation of Desertification Control in China, Higher Education Press, Beijing, 2011.

[16] H. Asenali, H. Siyiti, and A. Samuxi, "Evaluation of the implementation effect of grassland ecological compensation policy_- taking Yili River Valley as an example," Hubei Agriculture Science, vol. 60, no. 14, pp. 144-147+191, 2021.

[17] Z. Hu and C. Wang, "Evaluation of local government's social governance capacity and improvement path: taking Jiangsu Province as an example," Science and Technology and Industry, vol. 21, no. 06, pp. 52-57, 2021.

[18] B. Xue, Research on the Evaluation of Ecological Governance Policies from the Perspective of Farmers, Lanzhou University, Lanzhou, China, 2019.

[19] Z. Wang, Analyses the "Chinese Plan" of the World's Desertification Prevention and Control-Kubuqi Model, http:// env.people.com.cn/n1/2018/0207/c1010-29811615.html,\% 202018-\%2002-07, 2018.

[20] X. Wang and J. Zhang, "Co-governance based on symbiosis: the interpretation of the value of government ecological governance," Theoretical Discussion, vol. 217, no. 6, pp. 183190, 2020.

[21] Yi Hu, Research on Public Participation Rights under the Multi-Governance Environmental Governance System, Jilin University, Changchun, China, 2020.

[22] Yu Yue, Research on the Pursuit of Value Goals and Realization of Chinese Smart Government, Jilin University, Changchun, China, 2019.

[23] S. Wang and X. Liu, "The basis of trust: a rational explanation," Sociological Research, no. 3, pp. 12-17, 2002.

[24] America Francis Fukuyama, Trust: Social Virtues and Creating Economic Prosperity, p. 125, Yuanfang Publishing House, Hohhot, 1998. 